\title{
UMA ABORDAGEM DIFERENCIADA PARA O ENSINO DO TEMA SAÚDE NO ENSINO MÉDIO
}

\author{
UN ENFOQUE DIFERENCIADO A LA EDUCACIÓN EN SALUD EN LA ESCUELA \\ SECUNDARIA
}

A DIFFERENTIATED APPROACH TO HEALTH EDUCATION IN HIGH SCHOOL

\author{
Claudio DIAS DA SILVA JUNIOR ${ }^{1}$ \\ Diana Natali da Silva BERTIN ${ }^{2}$ \\ Doriana DE LUCCA ${ }^{3}$ \\ Rosebelly Nunes MARQUES ${ }^{4}$
}

RESUMO: Jogos didáticos são instrumentos muito úteis para auxiliar o ensino nas escolas, principalmente para conteúdos mais complexos e de difícil fixação pelos alunos. O tema saúde abordado no ensino médio se encaixa no grupo de temas de difícil fixação pelos alunos, tendo em vista o número elevado de nomes e características a serem aprendidas, a utilização do jogo "San San da Saúde" veio como sugestão de uma forma diferente de abordar o tema, tornandoo mais divertido e amigável para os alunos. Observou-se que os alunos avaliaram de forma muito positiva os resultados do jogo como instrumento didático, dando indícios de que o aprendizado foi facilitado com a utilização do mesmo, principalmente em função de como este instrumento foi utilizado.

PALAVRAS-CHAVE: Saúde. Jogo didático. Metodologia ativa. Instrumento de ensino.

RESUMEN: Los juegos educativos son herramientas muy útiles para ayudar a enseñar en las escuelas, especialmente para contenido más complejo y difícil de arreglar para los estudiantes. El tema de la salud que se aborda en la escuela secundaria encaja en el grupo de temas difíciles de resolver por los estudiantes, dada la gran cantidad de nombres y características que deben aprenderse, el uso del juego "San San da Saúde" sugirió como una forma diferente de Aborde el tema haciéndolo más divertido y amigable para los estudiantes. Se observó que los estudiantes evaluaron los resultados del juego como un instrumento didáctico de manera muy positiva, dando evidencia de que el aprendizaje se facilitó con el uso del mismo, principalmente debido a cómo se utilizó este instrumento.

1 Instituição: Universidade de São Paulo (USP/ESALQ), Piracicaba - São Paulo - Brasil. Graduando em Engenharia Agronômica do Departamento de Economia. ORCID: https://orcid.org/0000-0003-4701-4269. Email: claudio.dias.silva@usp.br.

${ }^{2}$ Instituição: Universidade de São Paulo (USP/ESALQ), Piracicaba - São Paulo - Brasil. Graduando em Engenharia Agronômica do Departamento de Economia. ORCID: https://orcid.org/0000-0003-2660-0453. Email: diana.bertin@usp.br.

${ }^{3}$ Instituição: Escola Técnica Estadual Gustavo Teixeira (ETEC), São Pedro - São Paulo - Brasil. Docente do Departamento de Ciências da universidade. ORCID: https://orcid.org/0000-0002-7356-1226. Email: doriana.lucca@etec.sp.gov.br.

${ }^{4}$ Instituição: Universidade de São Paulo (USP/ ESALQ), Piracicaba - SP - Brasil. Docente do Departamento de Economia, Administração e Sociologia (LES). ORCID: https://orcid.org/0000-0002-8726-3211. E-mail: rosebelly.esalq@usp.br. 
PALABRAS CLAVE: Salud. Juego educativo. Metodología activa. Instrumento de enseñanza.

ABSTRACT: Educational games are very useful tools to help teaching in schools, especially for more complex content in which students have difficult to fix what they've learned. The health theme addressed in high school fits into the group of subjects difficult to fix by students, given the high number of names and characteristics to be learned, the use of the game "San San da Saúde" suggested as a different way of addressing the topic by making it more fun and friendly for students. It was observed that the students evaluated the results of the game, as a didactic instrument, in a very positive way, giving evidence that the learning was facilitated with its use, mainly due to how this instrument was used.

KEYWORDS: Health. Educational game. Active methodology. Teaching instrument.

\section{Introdução}

O debate sobre a qualidade da educação brasileira e a alocação de recursos para a área vem sendo alvo de diversas disputas ideológicas no cenário político-econômico atual. Essa conjuntura revela, muitas vezes, um discurso que põe em dúvida qual o verdadeiro papel do professor em sala de aula e como acontece a transposição didática dos conteúdos ensinados aos alunos. Com isso, principalmente no momento atual do país, a atualização do professor acerca de recursos didáticos inovadores, que resgatem a atenção do aluno para os conteúdos ensinados, que não compitam com outras tecnologias presentes em sala de aula, mas que não fazem parte do projeto pedagógico em um primeiro momento, como é o caso dos celulares, e que tornem o processo de aprendizado mais lúdico e divertido, deve ser incentivada e divulgada.

Dentro deste debate, torna-se muito importante a abordagem do assunto Doenças em sala de aula, de forma lúdica, leve e informativa para os alunos da faixa etária de 16 e 17 anos. Este assunto, muito negligenciado em salas de aulas e alvo de muitas críticas na atual conjuntura do país, torna-se muitas vezes um tabu e o professor precisa saber lidar com isto e aprender a abordar este tema de forma lúdica e interativa, para que os alunos compreendam a importância do tema não apenas como mais uma informação importante para o vestibular, mas sim como uma aula informativa para a vida dos alunos.

Para Mafuani (2012), a experiência docente que o estágio proporciona ao aluno é essencial para a formação integral, possibilitando o contato com o cotidiano de uma escola e com a prática docente. Muitas vezes, o aluno na universidade se depara com o conhecimento técnico-teórico e tem dificuldades de relacionar essa bagagem com o cotidiano pela falta da vivência. O estágio proporciona esse contato. 
Já Piaget (1970) colabora para a área educacional pelo lado da psicologia, assim como outros nomes bastante importantes. Ele fala do construtivismo, uma filosofia que acredita que o conhecimento é uma construção humana de significados, que procura fazer sentido no seu mundo. Essa concepção tem o aluno como agente ativo do processo de aprendizagem.

Vygotsky (1982) também acena com ideias parecidas a de Piaget, dizendo que o indivíduo não é resultado de um determinismo cultural, ou seja, não é um ser passivo, que só reage frente às pressões do meio, e sim um sujeito que realiza uma atividade organizadora na sua interação com o mundo.

Paulo Freire (1987) não concordava com práticas pedagógicas que transmitissem aos sujeitos um saber já construído, que defende em sua teoria da "educação bancária". Ele acreditava que o ato de educar deve contemplar o pensar e o concluir, contrapondo a simples reprodução de ideias impostas.

Esses autores reforçam os processos cognitivos de aprendizado e colaboram para a noção de aluno como agente ativo do processo de ensino-aprendizagem, e os recursos e instrumentos didáticos vem de encontro a essa ideia, trazendo novas concepções e formas de ensinar para dentro das salas de aula, tornando a transposição de assuntos muito mais dinâmica e interessante.

No contexto das metodologias ativas de ensino, estão os Jogos Didáticos, cujo objetivo é trazer o ensino de conteúdos de forma lúdica e com a participação ativa dos alunos. Os jogos possibilitam o desenvolvimento da criatividade, de habilidades de trabalho em equipe, estratégia e aprendizado efetivo. $\mathrm{O}$ uso dos jogos, quando bem aplicado, pode ter como principal destaque que o aprendizado dos conteúdos é altamente incorporado ao longo da partida, sendo o erro considerado como uma importante etapa, que é a discussão dos conteúdos em equipe (MARQUES, 2017).

Outro destaque ao uso dos Jogos Didáticos pode ser visto no trabalho de DE ALENCAR et al. (2019), demostrando que a discussão dos conteúdos ocorreu forma descontraída além de desenvolver no estudante postura autônoma e proativa em sala tornando-o protagonista na construção e compartilhamento do conhecimento.

No Ensino Médio, os conteúdos sobre doenças são abordados, mais especificamente, na disciplina de Biologia. Já no Curso de Engenharia Agronômica, estes são contemplados nas disciplinas Fitopatologia e Zoologia Geral.

No caso da Licenciatura, a discussão é sobre a construção de materiais didáticos, na disciplina LES0342 - Instrumentação para o ensino de Ciências Agrárias. As atividades fizeram parte do desenvolvimento do Estágio Supervisionado, no contexto da disciplina a disciplina 
LES0342 - Instrumentação para o ensino de Ciências Agrárias, do curso de Licenciatura em Ciências Agrárias da ESALQ/USP. O principal objetivo é incentivar o desenvolvimento de materiais didáticos, trazendo experiência teórico-prática para o futuro exercício docente, com as atividades práticas do estágio.

A partir desse contexto, o presente trabalho apresenta e discute a elaboração/aplicação de um Jogo Didático para o ensino de conteúdos relacionados a área da saúde no terceiro ano do ensino médio, com intuito de consolidar com os alunos o tema doenças abordados na disciplina de Biologia, além de contemplar a importância da prática docente na formação do licenciado em Ciências Agrárias.

\section{Metodologia}

\section{- Contextualização da escola parceira}

A escola funciona desde 2010 e possui 10 salas de aulas; 3 laboratórios de informática; 1 sala do grêmio e ATA - Assistente Técnico Administrativo; 1 laboratório de física, química e biologia; 1 biblioteca; 1 anfiteatro; 6 banheiros; 2 cozinhas com cantina; 1 secretaria acadêmica; 1 diretoria; 1 sala de coordenação; 1 secretaria administrativa e 1 sala dos professores (com cozinha). Atualmente possui 440 alunos, em 3 turnos, distribuídos em 6 turmas de ensino médio regular; 3 turmas de ensino médio integrado ao técnico (ETIM); 1 turma de técnico em Marketing; 1 turma de técnico em Finanças e 1 turma de técnico em Recursos Humanos. Conta ainda com 60 funcionários, nos setores administrativos, pedagógico e terceirizado.

Tanto o ensino médio regular como o ETIM estão organizados em 3 séries anuais, nas quais as disciplinas curriculares estão distribuídas. Após o ingresso, o aluno é avaliado em cada componente curricular levando-se em consideração a análise de suas competências, habilidades e valores, além das bases tecnológicas e científicas pertinentes de cada área do conhecimento. Neste contexto, práticas diversificadas, são bem aceitas e exploradas pelos estudantes que constantemente desenvolvem projetos integrados às disciplinas curriculares.

\section{- Desenvolvimento do jogo}

A escolha da temática do jogo foi feita com base em observações semanais em duas turmas do ensino médio, para que fosse possível compreender a turma, seu comportamento, suas necessidades e até mesmo interesses. Além disso, foram realizadas reuniões com a professora de biologia da turma para compreender os desafios enfrentados pela mesma, em 
seguida foi discutida a idéia do jogo e o conteúdo ao qual ele se aplicava, saúde para o ensino médio, voltado para doenças.

Para o desenvolvimento do jogo, baseou-se no trabalho de DELLA ANTONIA et al. (2017), onde foi desenvolvido um jogo "San San” para trabalhar a temática de composição química dos alimentos, com foco em nutrientes reguladores. Tendo em vista os bons resultados observados no trabalho e a dificuldade observada por parte dos alunos com o tema saúde, em função dos muitos nomes científicos e termos técnicos, desenvolveu-se um jogo do mesmo tipo para as doenças, chamado de "San San da Saúde", em que o aluno encontra de forma resumida e facilitada as informações mais relevantes sobre cada uma das principais doenças trabalhadas pelo professor, incluindo as principais DST's.

O tabuleiro e as cartas do jogo foram montados no programa Microsoft Office PowerPoint. As doenças escolhidas e as informações sobre as mesmas foram retiradas de aulas voltadas para o ensino médio, com a intenção de trabalhar o conteúdo da forma mais realista possível, se aproximando ao máximo do que é trabalhado em sala de aula.

O tabuleiro e as cartas foram impressos em papel cartão nos respectivos tamanhos de folha $\mathrm{A} 3 \mathrm{e} 4$ x 3,11 cm, como pode ser observado nas imagens abaixo.

Figura 1 - Tabuleiros do jogo "San San da Saúde".

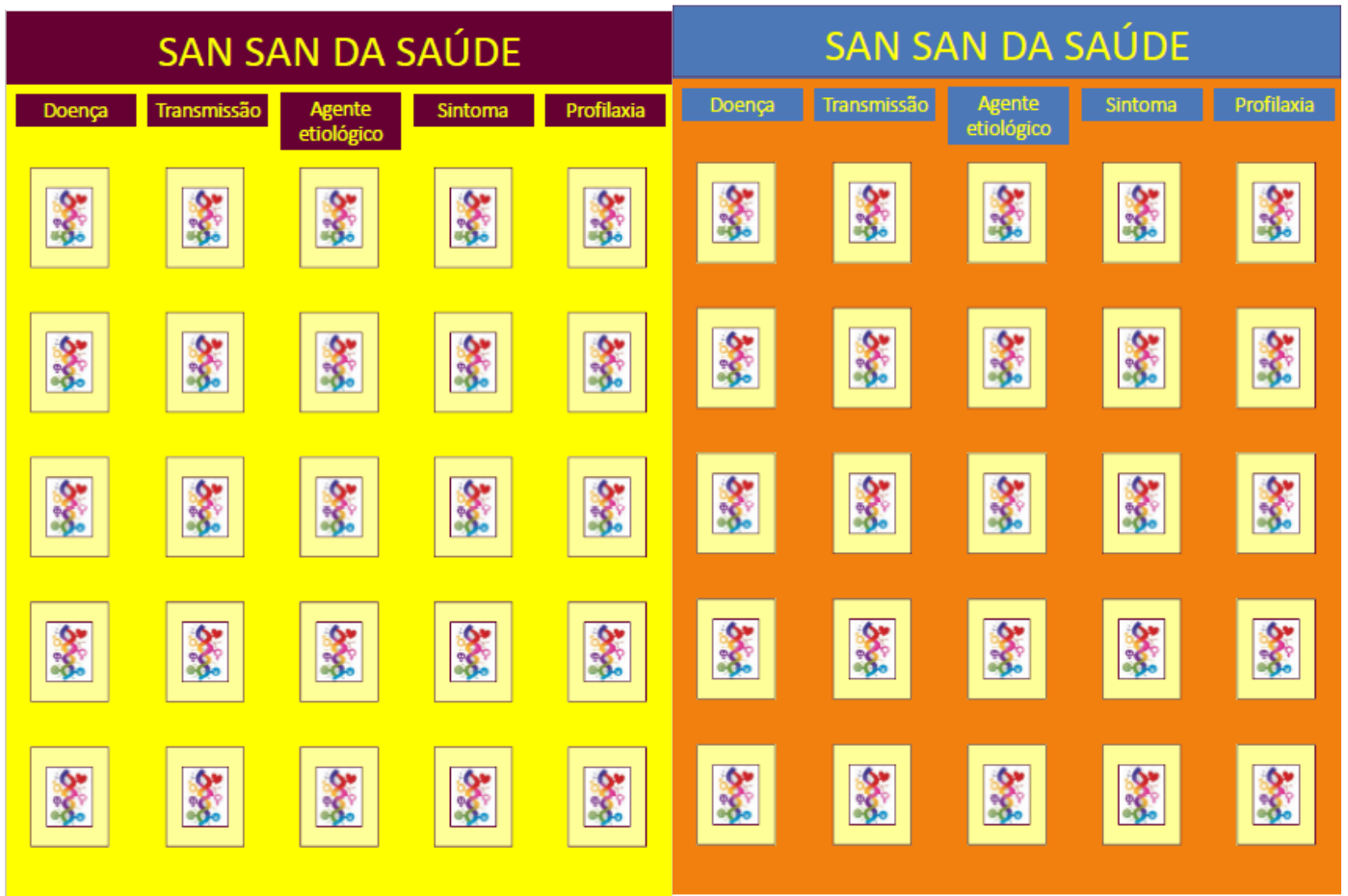

Fonte: elaborado pelos autores. 
Figura 2 - Conjunto de cartas da doença dengue exemplificando as peças do jogo.
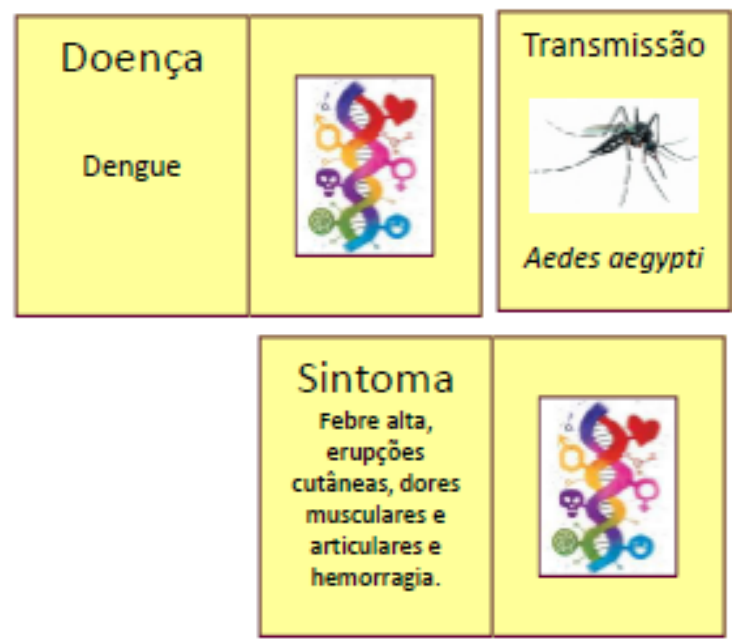
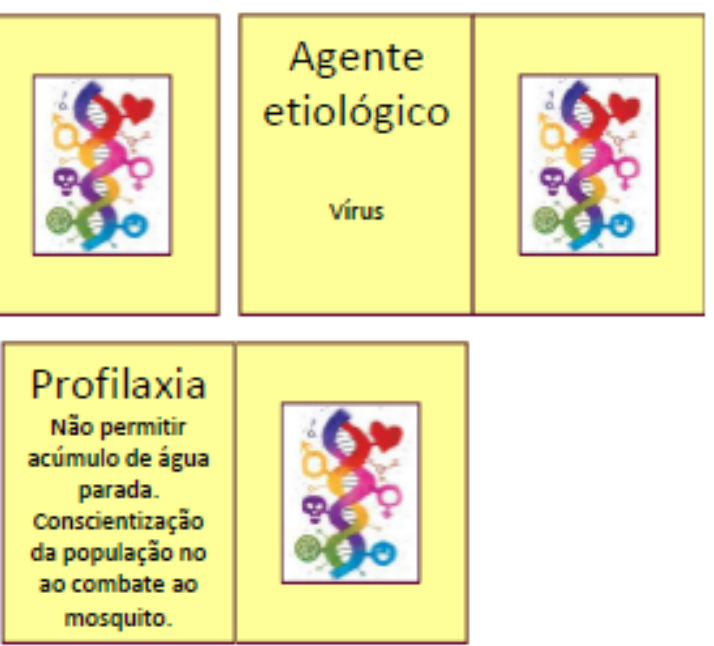

Fonte: elaborado pelos autores.

O tabuleiro foi impresso em duas diferentes escalas de cores, sendo assim, um jogo é composto por dois tabuleiros, cada um contendo 27 doenças, ou seja, 135 cartas e um manual de regras com gabarito, mostrando todas as doenças e suas respectivas combinações.

Figura 3 - Imagem do livro de regras e gabarito, exemplificando como este é constituído.

SAN SAN DA SAÚDE

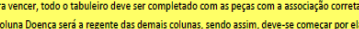

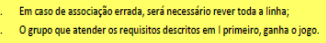

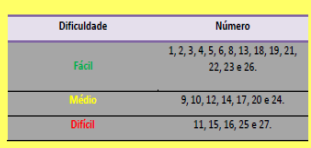

Autores: Claudio Dias da Sivva Junior e Diana Natali da Siva Bettin

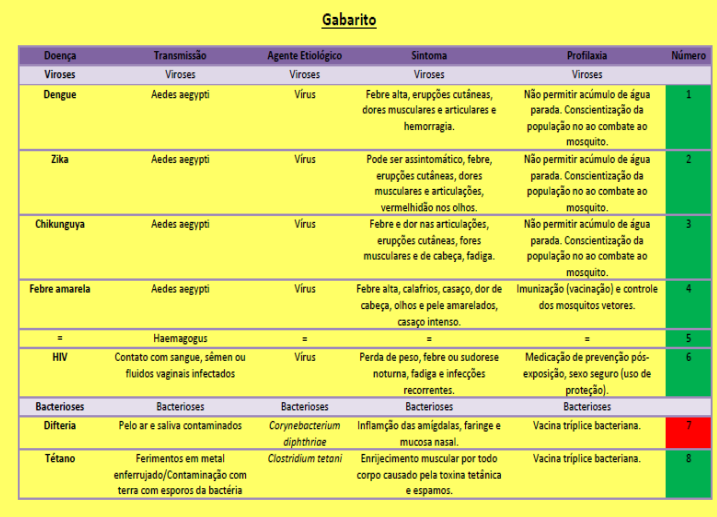

Autores: Claudio Dias da Siviva Junior e Diana Natal ida Sivva Bertin

Fonte: elaborado pelos autores. 
Quadro 1 - Materiais e tempo de preparo do jogo

\begin{tabular}{|l|lc|}
\hline \multicolumn{1}{|c|}{ Materiais } & \multicolumn{1}{c|}{ Preparo } & \multicolumn{1}{c|}{ Tempo } \\
\hline Plastificadora & Estudo do conteúdo & 2 semanas \\
Papel cartão & Adequação do conteúdo ao & \\
Folha de sulfite & jogo & 2 semanas \\
Impressora & Preparo das cartas e tabuleiros & 2 semanas \\
Computador & Cortes & 1 semana \\
Software Microsoft Office PowerPoint ou & Plastificação & 1 semana \\
equivalente & & \\
Guilhotina & Aplicações teste & 4 semanas \\
\cline { 2 - 3 } & Total & 12 semanas \\
\hline
\end{tabular}

Fonte: elaborado pelos autores.

No gabarito, é possível observar as diferentes cores atribuídas em todas as doenças, estas que definem o nível de dificuldade para que os alunos realizem a associação correta daquela doença, considerando a popularidade da doença e também a semelhança com outras doenças em questão de sintomatologia e profilaxia.

\section{- Aplicação do jogo}

Para a aplicação do jogo foi seguido o mesmo procedimento em ambas as salas. A sala foi dividida em quatro grupos com números iguais de alunos. Após a divisão as regras do jogo foram explicadas, assim como seu funcionamento. Em cada sala possuíamos quatro tabuleiros com diferentes combinações de cartas e doenças. Foram realizadas quatro rodadas, ao final de cada rodada os tabuleiros passavam de um grupo para o outro para mudar as doenças.

Na primeira rodada os alunos foram deixados livres para utilizar material de consulta e perguntarem suas dúvidas sobre o jogo. Após esta primeira rodada, as três seguintes foram feitas em formato de competição, o grupo ganhador seria aquele que terminasse primeiro e com a combinação correta das cartas. Para as quatro rodadas foram gastos 50 minutos de aula (aula padrão), considerando jogo e correção dos tabuleiros ao final de cada rodada.

\section{- Coleta de dados}

A obtenção dos dados foi feita em duas etapas, sendo a primeira a observação diagnóstica semanal e a segunda, o questionário diagnóstico respondido pelos alunos e também pela professora.

O questionário dos alunos era composto de quatro questões, tendo por objetivo entender como o jogo foi percebido pelos alunos, sendo composto pelas questões "Você gostou do jogo? 
Qual foi a sua impressão sobre ele?", "Você sugere alguma mudança para as regras ou para a forma de jogar?", "Você acha que aprendeu melhor o tema jogando? Qual sua opinião sobre usar jogos nas aulas?" e "Tem alguma sugestão para melhoria?".

O questionário para a professora teve por objetivo entender do ponto de vista do professor, como o jogo pode contribuir com o ensino e com a aula, assim como o interesse do mesmo neste instrumento didático, foi composto por cinco questões, sendo elas: "Já utilizou este tipo de instrumento antes? Se sim, poderia comentar sobre?", “Quais foram suas observações com relação aos alunos? Acredita que o jogo foi benéfico?", "Com base em sua observação, como foi a participação dos alunos na atividade? Desenvolveria mais atividades do tipo com eles?", "Você acredita que este tipo de atividade seja importante? Poderia explicar o motivo?”, “Tem alguma sugestão para melhoria do jogo ou de sua aplicação? Existe algum tema para o qual gostaria de adaptá-lo?’.

\section{Resultados}

\section{- Observação diagnóstica}

Observou-se que com a aplicação do jogo "San San da Saúde" os alunos demonstraram melhor aceitação do conteúdo. Mesmo antes de colocar a ideia de competição entre os grupos, parte dos alunos já se mostravam bastante interessados pelo jogo, mesmo sendo simples, provavelmente por ser uma ideia de uma aula diferenciada. Foi perceptível que quando colocado o fator competição, o interesse dos alunos por ganhar foi grande, aumentando ainda mais a aceitação do jogo.

Como resultado das observações diagnósticas, notou-se que as salas observadas eram bastante diferentes, isso se refletiu também na aplicação do jogo. Na sala do $3{ }^{\circ} \mathrm{C}$ a aplicação foi bastante tranquila, os alunos gostaram muito de participar do jogo e ainda deram um retorno com relação ao que acharam ao final da atividade. Durante a aplicação todos seguiram as regras e tiraram muitas dúvidas no momento da correção. Como retorno, disseram que o jogo é bastante intuitivo e interessante, eles sentiram certa confusão na parte de sintomatologia em função da semelhança entre algumas doenças.

Na sala do $3^{\circ} \mathrm{A}$, uma sala mais agitada, tivemos problemas inicialmente com alunos que tentavam observar as respostas de outro grupo e até mesmo esconder cartas para não permitir que outros grupos completassem o tabuleiro. Nesta sala o retorno que recebemos foi que os grupos deveriam ser menores, pois grupos grandes como os formados (mais ou menos entre 7 
e 8 alunos) não eram bons para organizar a equipe e completar o tabuleiro do jogo, pois um aluno acabava se intrometendo no que o outro fazia e causando confusão.

Com relação à professora, ela adorou o jogo montado, querendo inclusive utilizá-lo como avaliação desta parte da matéria. Ela se surpreendeu com a forma como os alunos se interessaram em resolver o jogo, mostrando um interesse no assunto que não surgiu durante a aula.

\section{- Questionário diagnóstico dos alunos}

O questionário diagnóstico foi aplicado em ambas as salas, foram obtidas 42 respostas dos alunos.

\section{Você gostou do jogo? Qual foi sua impressão sobre ele?}

Para esta questão, os 42 alunos responderam que sim, demonstrando a grande aceitação do jogo pelos mesmos. Dentre as respostas, as impressões que mais se destacaram foram que o jogo é bastante simples, mas o fato de ser jogado em grupo e no formato de competição o torna muito interessante, o que nos mostra que o fator competição foi essencial para a aceitação do jogo. Alguns alunos ainda destacaram que por ser um jogo de associação, os auxiliou a lembrar as características das doenças posteriormente com mais facilidade.

\section{Você sugere alguma mudança para as regras ou para a forma de jogar?}

Nesta questão, a maior parte dos alunos respondeu que não, que o jogo estava bom da forma como foi aplicado. Porém, alguns alunos levantaram pontos para melhorar a jogabilidade.

Foram levantados três pontos, sendo eles na ordem de mais citados, a separação em grupos com menos alunos, para melhorar a interação do grupo e facilitar a organização do mesmo durante o jogo, na sala foram separados quatro grupos de 7 a 8 alunos, a sugestão foi para grupos de 3 a 4 alunos. Outro ponto foi o controle do tempo, os alunos sugeriram que esse fosse cronometrado durante a partida, durante a aplicação não foi controlado o tempo, deixando que o primeiro a terminar ganhasse, mas na sugestão dos alunos o tempo deveria ser controlado, e caso terminasse antes que um grupo completasse o tabuleiro, aquele com o mais completo ganhasse, porém este quesito fica a critério do professor, pois não traz grandes diferenças, apenas possibilita melhor controle do tempo de aula. A última sugestão levantada foi o critério de desempate, durante a aplicação do jogo foi considerado no caso de grupos que terminaram juntos, aquele que não cometeu nenhum erro de associação, no caso de ambos estarem corretos, ambos ganhavam o ponto, no caso de ambos errarem, ninguém ganhava, mesmo que um grupo tivesse cometido menos erros. 
Gráfico 1 - Respostas dos alunos a questão II

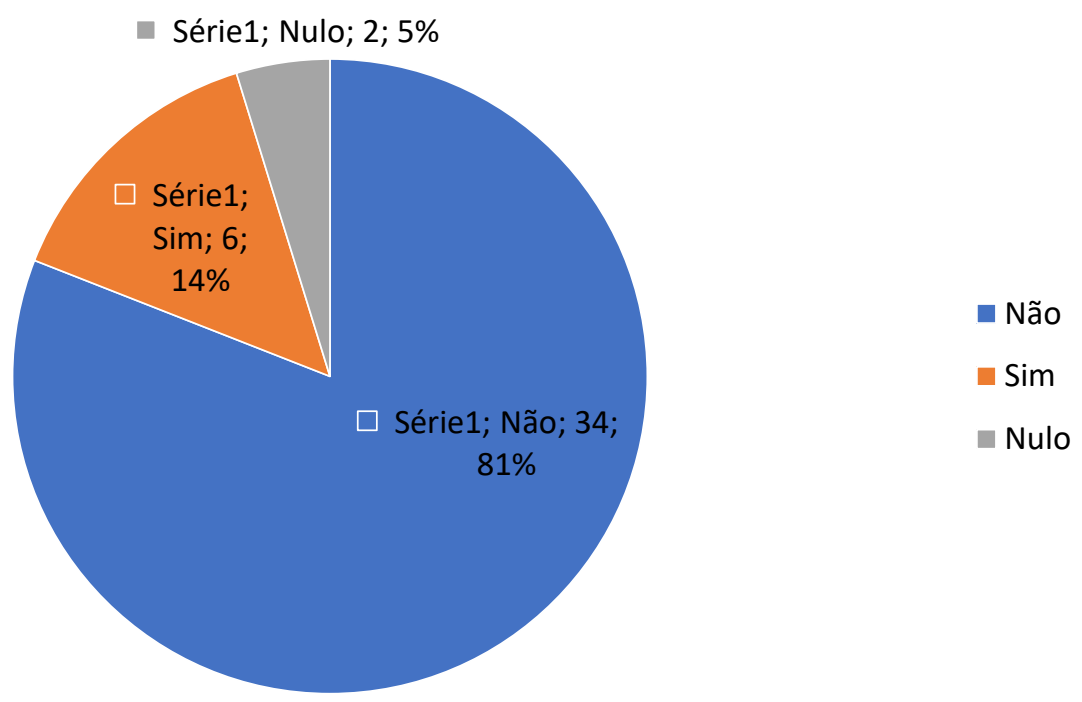

Fonte: elaborado pelos autores.

\section{Você acha que aprendeu melhor o tema jogando? Qual sua opinião sobre usar jogos nas aulas?}

Nesta pergunta, as 42 respostas obtidas foram sim, mostrando que todos os alunos acreditam ter aprendido melhor através da utilização do jogo dentro da sequência didática elaborada pela professora para tratar sobre o tema saúde. Dentre as opiniões dos alunos, grande parte citou ter fixado melhor o conteúdo, assim como compreendido melhor o mesmo após realizar as associações durante as rodadas, observando cada doença de modo isolado, associando a profilaxia, o agente etiológico, o vetor e os sintomas a cada doença disponível. Alguns alunos comentaram sobre a importância do trabalho em grupo proposto pelo jogo também, possibilitando melhor interação entre os mesmos e como a competição entre os grupos os motivou a entender melhor o tema para ganhar durante as rodadas, mostrando mais uma vez a grande importância da competição para a dinâmica do jogo.

Algumas opiniões se destacaram em meio às respostas, como a de um aluno que citou que pôde entender algumas questões, durante o jogo, que ainda não tinha compreendido do conteúdo, mostrando que o jogo pode ser utilizado como revisão ao final de uma sequência didática, buscando suprir dificuldades que tenham ficado ao longo da apresentação do conteúdo.

Outra opinião que se destacou foi que o jogo ajudou bastante no conteúdo, mas que deve ser algo utilizado com frequência e não apenas uma vez, pois é uma atividade que se aplicada 
apenas uma vez com cunho de revisão terá menor eficácia. Ainda na questão da repetição, um aluno levantou a questão de utilizar o jogo como avaliação, algo que seria bastante cabível no caso de apenas uma aplicação, porém, a forma de aplicar deveria ser diferente, talvez obrigando todos os grupos a completarem o tabuleiro e avaliando em função do número de erros.

Um ponto negativo que se pode observar nas opiniões, é que muitos alunos utilizaram palavras como "decorar" e "memorizar", o que não seria o intuído do jogo, o intuito era motiválos a aprender para poder jogar melhor, sendo necessário repensar o momento de aplicar o jogo, para motivá-los, talvez se o jogo fosse aplicado antes da sequência didática e no final, com cunho avaliativo, o impacto fosse melhor, levando-os a estudar o conteúdo e não a apenas a tentar decorá-lo.

\section{Tem alguma sugestão para melhoria?}

Para esta pergunta obtivemos muitas sugestões dos alunos, o que foi muito interessante do ponto de vista de melhoria do jogo, a divisão das respostas obtidas pode ser observada no gráfico a baixo.

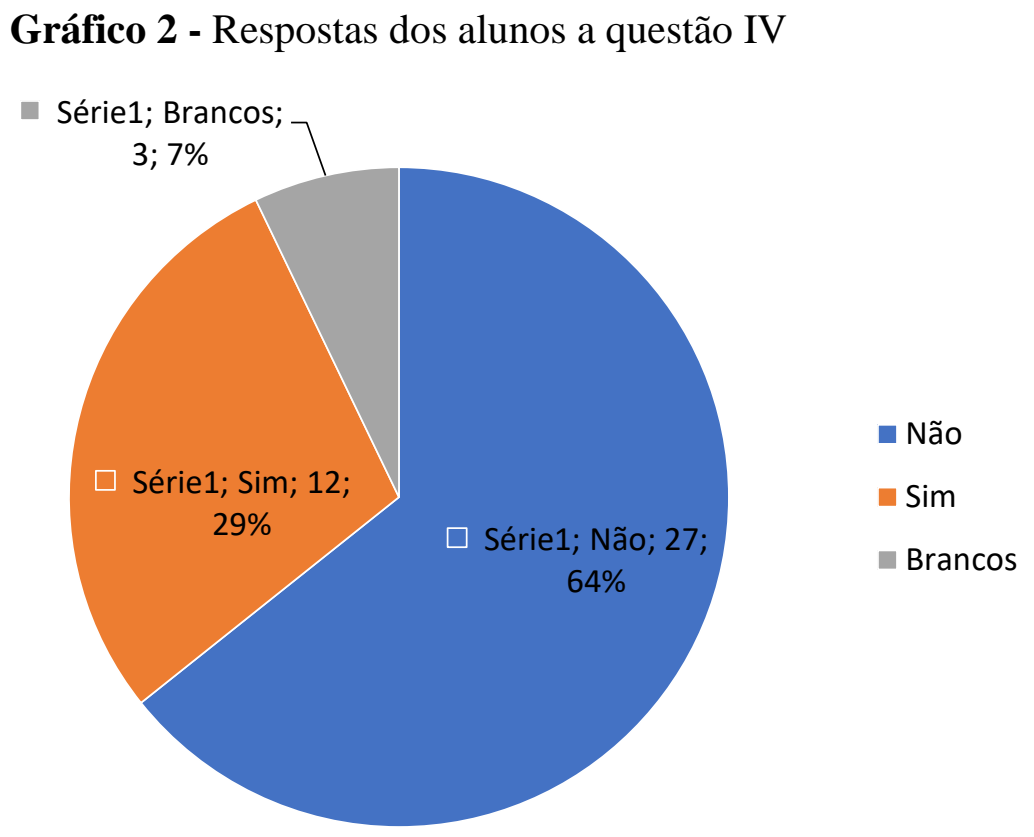

Fonte: elaborado pelos autores.

A principal sugestão obtida a partir das respostas dos alunos foi, novamente, a formação de grupos com menos alunos, acredito que este tenha sido o principal problema durante a aplicação do jogo do ponto de vista dos alunos. Como segunda sugestão mais comum, apareceu o controle do tempo, porém, dentro desta sugestão temos duas requisições diferentes, alguns alunos acham que deveria haver um tempo pré-estipulado para que o jogo se desenvolvesse, 
outros já acreditam que cronometrar quanto tempo eles levam para resolver como forma de competição já seria o suficiente.

Foram observadas também sugestões pontuais, como uma forma de fixar às peças no tabuleiro, para evitar que as associações já realizadas se perdessem, a mudança da cor das peças de cada coluna, facilitando identificar a que coluna cada carta é referente com maior facilidade, o aumento no número de aplicações do jogo, utilizando em mais de uma aula, e por fim, maior interdisciplinaridade no jogo, algo que pode ser conquistado com a criatividade no momento de criar as cartas ou até mesmo com a expansão do tabuleiro, adicionando novas colunas.

\section{- Questionário diagnóstico do professor}

Observando as respostas obtidas da professora, nota-se que, de seu ponto de vista, a utilização do jogo agregou muito a aula e aos estudantes, por exemplo, quando questionada quanto a participação dos alunos na atividade, sua resposta foi: "Eles se sentiram desafiados. Foi interessante que eles tinham que discutir com os colegas para chegar a um consenso para propor a solução para o jogo". Além disso, a professora disse acreditar que os jogos são muito importantes no processo educativo, principalmente os cooperativos, que possibilitam que os estudantes desenvolvam habilidades de trabalho em equipe.

Quando questionada se já utilizou este tipo de instrumento antes, a professora disse que sim, que aplicava jogos já existentes e até mesmo tentou criar um Super Trunfo sobre tecidos humanos com alunos do $8^{\circ}$ ano, mostrando sua aceitação a este tipo de material. O interesse da professora em utilizar jogos didáticos foi mais uma vez demonstrado quando questionada se desenvolveria mais atividades do tipo com os alunos, quando ela respondeu que gostaria muito e seria muito interessante, porém, em suas palavras "a sobrecarga de aulas e escolas acaba dificultando este trabalho", resposta esta que evidencia uma realidade amarga enfrentada pelos educadores atualmente.

Quanto a sugestões da professora, novamente aparece a questão de grupos menores, ela enfatizou que alguns alunos ficam retraídos em meio a grupos grandes, o que não permite que aproveitem a dinâmica. Quando questionada se acredita na possibilidade de adaptação do jogo para outros temas, a professora acredita que exista a possibilidade de adaptação do jogo para outros conteúdos, como ecologia e seres vivos. 


\section{Considerações finais}

Observa-se que para os alunos, o fator competição foi o que captou a atenção e causou a melhor aceitação do jogo, mesmo tendo em vista sua simplicidade. Os alunos se sentiram envolvidos pela ideia do trabalho em grupo, porém tiveram problemas com os grupos muito grandes, o que deixa claro que para que o jogo flua melhor, em futuras aplicações, deve-se utilizar grupos menores. Outro ponto a se atentar com relação aos alunos é o cuidado para que não entendam como um jogo para decorar o conteúdo e sim como um jogo para testar seus conhecimentos sobre o tema, levando-os a estudar previamente.

Nota-se também que, mesmo sendo uma atividade bastante enriquecedora, existe uma dificuldade para a elaboração e preparação de um jogo por causa do fator tempo, que é limitante para os educadores brasileiros, o que evidencia a importância de trabalhos nos quais sejam desenvolvidos jogos que permitam ao educador apenas ler e ser capaz de preparar e aplicá-los aos alunos.

A metodologia desenvolvida foi facilitadora no processo de ensino e aprendizagem e foi bem aceita pelos estudantes e pela professora, além de contribuir para a formação dos licenciandos envolvidos ativamente no processo.

AGRADECIMENTOS: Os autores agradecem à Direção da ETEC Gustavo Teixeira, São Pedro/SP à pró-reitoria de Graduação da USP pelo apoio no desenvolvimento das atividades.

\section{REFERÊNCIAS}

ANTONIA, B. D.; FUJIWARA, R. I.; MARQUES, R. N. O jogo San San como recurso didático de apoio nas discussões sobre nutrientes reguladores no ensino fundamental. Temas em Educação e Saúde, [S.1.], p. 301-316, nov. 2017. ISSN 2526-3471. Disponível em: https://periodicos.fclar.unesp.br/tes/article/view/10679. Acesso em: 22 sep. 2019. DOI: https://doi.org/10.26673/rtes.v13.n2.jul-dez.2017.10679.

DE ALENCAR, E. S.; DE OLIVEIRA, M. dos S. Matemática nos jogos e brincadeiras na educação infantil em pesquisas brasileiras. Revista Areté - Revista Amazônica de Ensino de Ciências, v. 11, n. 24, p. 87-103, 2019.

FREIRE, P. Pedagogia do oprimido. 17. ed. Rio de Janeiro: Paz e Terra, 1987.

MAFUANI, F. Estágio e sua importância para a formação do universitário. Instituto de Ensino superior de Bauru, 2011. 
MARQUES, R. N. Considerações sobre metodologia e recursos didáticos de ensino: limites de possibilidades. In: MASSABNI, V. G. Ensaios pedagógicos e a docência no ensino superior, Ribeirão Preto: Funpec Editora, 2017.

PIAGET, J. Psicologia e pedagogia. Tradução de Dirceu Accioly Lindoso e Rosa Maria Ribeiro da Silva. São Paulo e Rio de Janeiro: Editora Forense, 1970.

VYGOTSKY, L. S. Obras escolhidas: problemas de psicologia geral. Fuenlabrada, Madrid: Gráficas Rogar. 1982. 387 p.

WACHHOLZ, G. R.; ARROSI, R. M.; DE ANTONI, C. Elaboração e aplicação do jogo de tabuleiro 'caminhando pelo sus': relato de experiência. Temas em Educação e Saúde, [S.1.], p. 159-168, jul. 2019. ISSN 2526-3471. Disponível em:

https://periodicos.fclar.unesp.br/tes/article/view/12092/8362. Acesso em: 22 sep. 2019. DOI: https://doi.org/10.26673/tes.v15i1.12092.

\section{Como referenciar este artigo}

DIAS DA SILVA JUNIOR, Claudio; BERTIN, Diana Natali da Silva; DE LUCCA, Doriana; MARQUES, Rosebelly Nunes. Uma abordagem diferenciada para o ensino do tema saúde no ensino médio. Temas em Educ. e Saúde, Araraquara, v. 15, n. 2, p. 234-247, jul./dez. 2019. eISSN 2526-3471. DOI: https://doi.org/10.26673/tes.v15i2.13056

Submetido em: 20/02/2019

Revisões requeridas: $15 / 03 / 2019$

Aprovado em: 30/04/2019

Publicado em: 30/07/2019 